\title{
Formação continuada enquanto ética do cuidado de si
}

\author{
Continuing education as an ethic of self-care
}

\section{Formación continuada como ética del cuidado con uno mismo}

\author{
Miguel da Silua Rossetto' \\ Universidade de Passo Fundo, Instituto de Filosofia e Ciências Humanas, Professor. \\ https://orcid.org/0000-0001-6889-7983 \\ Marcelo José Doro² \\ Universidade de Passo Fundo, Curso de Filosofia e Área de Ética e Conhecimento, Professor. \\ https://orcid.org/0000-0001-9765-1958
}

Resumo: Este trabalho investiga alguns pressupostos filosóficos de modelos ou formas de efetivação dos processos de formação continuada de professores. Partimos da apreciação crítica de dois grandes paradigmas fundamentais que sustentam concepções distintas de formação continuada, quais sejam, o "modelo tradicional de formação continuada", calcado em uma perspectiva metafísica; e o "modelo contemporâneo de formação continuada", calcado na gestão de si mesmo. Como aporte crítico-conceitual para dialogar com esses dois modelos e, especialmente, para prospectar novos pressupostos filosóficos para a formação continuada, investigamos a noção de cuidado de si, de Michel Foucault, tomando como base a obra A Hermenêtica do Sujeito. Com base na investigação interpretativa da filosofia de Foucault, concluímos que a modalidade continuada de formação de professores, quando tem seus pressupostos relegados a terceiros, não atende integralmente ao que julgamos ser sua principal finalidade, a saber, a transformação ética do educador. Em síntese, em consequência da pesquisa, essa finalidade é, em grande parte, alcançada, uma vez que a própria realidade do educador e seus diferentes problemas tornam-se objeto de estudo, pesquisa e reflexão, de modo que o conhecimento resultante desse processo, uma vez incorporado à prática do educador conduz à transformação ética do si mesmo.

Palavras-chave: Formação continuada. Cuidado de si. Ética e formação humana.

Abstract: This work intends to investigate some philosophical assumptions of teachers' continuous formation processes effectiveness models or forms. We start from the critical appraisal of two great fundamental paradigms that support different conceptions of continuous education, namely the "traditional

Doutor e Mestre em Educação pela Universidade de Passo Fundo.

2 Doutor em Educação pela Universidade de Passo Fundo; Mestre em Filosofia pela Universidade Federal de Santa Catarina. 
model of continuous education", based on a metaphysical perspective, and the "contemporary model of continuous education", based on the management of oneself. As a critical and conceptual contribution to dialogue with these two models and, especially, to prospect new philosophical assumptions for continuous education, we investigate Michel Foucault's notion of self-care, from The Hermeneutics of the Subject. On the basis of an interpretative investigation of Foucault's philosophy, we conclude that the continuous modality of teacher training, when it has its assumptions relegated to third parties, does not answer in full to what we think is its main purpose, namely, the ethical transformation of the educator. In short, as a result of the research, this purpose is, largely, achieved, once the educator's reality and its different problems become object of study, research and reflection, so that the resulting knowledge from this process, when it is incorporated into the educator's practice, leads to the ethical transformation of the self.

Keywords: Continuous formation. Self care. Ethics and human formation.

Resumen: Este trabajo pretende investigar algunos supuestos filosóficos de modelos o formas de efectividad de los procesos de formación continua de profesores. Partimos desde la apreciación crítica de dos grandes paradigmas fundamentales que sostienen concepciones distintas de formación continua, que son el "modelo tradicional de formación continua", basado en una perspectiva metafísica, y el "modelo contemporáneo de formación continua", basado en la gestión de uno mismo. Como soporte crítico-conceptual para el diálogo con esos dos modelos $y$, especialmente, para prospectar nuevos supuestos filosóficos para la formación continua, investigamos la noción de cuidado con uno mismo, de Michel Foucault, teniendo como base La Hermenéutica del Sujeto. Desde la investigación interpretativa de la filosofía de Foucault, concluimos que la modalidad continua de formación de profesores, cuando presentan supuestos relegados a otros, no contempla integralmente a lo que juzgamos ser su principal finalidad: la transformación ética del educador. En síntesis, como consecuencia de investigación, esa finalidad es, en gran medida, alcanzada, una vez que la propia realidad del educador y sus diferentes problemas se conviertan en objeto de estudio, investigación y reflexión, de modo que el conocimiento resultante de ese proceso, una vez incorporado a la práctica del educador, conduce a la transformación ética de uno mismo.

Palabras-clave: Formación continua. Cuidado con uno mismo. Ética y formación humana.

Recebido em 1 de setembro de 2019

Aceito em 11 de agosto 2020

Publicado em 24 de setembro de 2020 


\section{INTRODUÇÃO}

A transformação do mundo diante da nova economia, da globalização, dos impactos da tecnologia em campos como a cultura e a educação, do rompimento de barreiras geográficas e de comunicação, que outrora conservavam culturas e costumes cerceados, e ademais aspectos plurais e transitórios que demarcam o contexto social atual justificam a necessidade de formação constante daqueles que, por excelência, formam o outro. ${ }^{3}$ Sem o devido compromisso do educador em continuar se aperfeiçoando, o vazio entre sua formação inicial $^{4}$ e o sentido dos processos pedagógicos no mundo atual alarga-se com rapidez. Invariavelmente, a titulação do educador torna-se insuficiente para formar o educando e isso faz emergir a questão da responsabilidade ética do educador com a continuidade de sua própria formação.

A formação continuada é uma exigência legal $\left.\right|^{5}$ e, como tal, é pauta lembrada e planejada anualmente pelas redes de ensino (pública e privada) de nosso país. Para sua realização, inúmeros eventos, tanto em nível nacional quanto regional, são promovidos regularmente. 0 que queremos problematizar, no entanto, não é a exigência de uma formação continuada e nem o esforço para sua realização, mas o seu sentido. No Art. 67, Inciso II, da Lei de Diretrizes e Bases (Lei n. 9394/96), essa modalidade de formação é nomeada de "aperfeiçoamento profissional continuado". ${ }^{6}$ Nossa preocupação, nesse contexto, volta-se para a compreensão de diferentes questões, a saber: em que consiste esse aperfeiçoamento? Sob que pressupostos teóricos ele se desenvolve hoje? Há necessidade de ressignificar esse espaço de formação?

Nesse sentido, considerando a evidência de que os processos de formação (aperfeiçoamento) acontecem sob a tensão entre um corpus de conhecimento (verdade) e a constituição do sujeito (subjetividade), recorremos ao diagnóstico crítico de Michel Foucault apresentado no curso $A$ hermenêutica do Sujeito, proferido em 1982, para descrever e denunciar uma situação pertinente a essa problemática. 0 núcleo temático do curso é o estudo das relações entre sujeito e verdade, guiadas pela noção de cuidado de si. A tese essencial, apresentada por Foucault, é de que, (1) por muito tempo, a tradição filosófica antiga colocou como condição para a obtenção da verdade a transformação espiritual do sujeito que, no fim, também será transformado pela verdade por ele acessada; e (2) esse entendimento foi

\footnotetext{
Sobre a temática das sociedades contemporâneas e os impactos na formação humana, sugere-se leitura de Mühl, Dalbosco e Cenci (2016).

4 Com a expressão "formação inicial do educador", referimo-nos à formação mínima exigida para atuar como professor, que, geralmente, acontece antes da própria atuação em sala de aula e, por consequência, antes da "formação continuada". Conforme Art. 67, Inciso II, da LDB 9394/96 (BRASIL, 2017).

6 Faremos opção pode usar a expressão "formação continuada", por ser a forma mais usada no cotidiano escolar.
} 
radicalmente alterado com o advento da modernidade filosófica, quando as condições para a obtenção da verdade tornaram-se restritas ao ato de conhecimento, de modo que o sujeito pode reconhecer e ter acesso à verdade sem que sua condição de sujeito seja posta em questão, sem qualquer exigência de que seu ser seja modificado ou alterado. A consequência disso, justamente aquilo que nos interessa marcar para a continuidade de nossa discussão, é que o modo de acesso à verdade, que desde a modernidade se dá exclusivamente por meio do conhecimento, já não encontra na verdade uma força transformadora: uma vez que o sujeito já não se "prepara", no sentido de alterar seu próprio ser para o reconhecimento da verdade, esta tampouco tem qualquer força retroativa sobre ele. Nas palavras do próprio Foucault (2004, p. 24): "Tal como doravante [desde a modernidade] ela é, a verdade não é capaz de salvar o sujeito."

0 diagnóstico de Foucault atesta a impossibilidade de salvarmos a subjetividade a partir de um modo específico de relação com a verdade, com aquela verdade que, desde a modernidade, mostra-se no e pelo conhecimento. Contudo, ao mesmo tempo em que recusa esse caminho específico, ele preserva a possibilidade de outro, no qual uma relação distinta com a verdade ainda permitiria "salvar o sujeito". Mas que caminho seria esse? Que relação com a verdade ele estabelece? Como tal caminho permitiria salvar o sujeito? Salvar o sujeito de quê? Para quê? De que forma? 0 sujeito, de fato, precisa ser salvo? Essas questões suscitadas pela constatação de Foucault convidam a reposicionar o sentido da relação entre verdade e subjetividade. A configuração de tal relação tem impactos imediatos sobre o processo de formação continuada do educador na atualidade.

0 lugar que a verdade ocupa e o papel que ela desempenha quando nos referimos à formação precisam ser reconhecidos em relação à influência que exercem sobre o modo como nos compreendemos enquanto possíveis sujeitos, ou não, da nossa própria formação. Esse contexto nos orienta a tratar do tema não necessariamente do ponto de vista legal, mas, eminentemente, do ponto de vista ético. Nesse percurso, o núcleo do problema deste ensaio se configura a partir da seguinte ponderação: a partir de que relação com a verdade o educador deveria operar sua formação continuada, especificamente, quando se tem em vista a formação ética do si mesmo?

Para tratar desse problema, apresentamos três perspectivas de formação continuada em que os impactos das políticas da verdade ${ }^{7}$ sobre o sujeito são decisivos. Primeiramente, voltamos nosso olhar para o modelo tradicional de formação continuada, que, radicado em uma concepção metafísica de verdade, oferece uma noção forte de teoria. Tal modelo impossibilita a transformação ética do si mesmo, uma vez que prioriza a verdade em detrimento do sujeito e de seu campo de experiências prático-pedagógicas.

Sobre a noção de "políticas da verdade", conferir Foucault (2014b). 
Na sequência, apresentamos outro modo eminente de configuração da concepção de verdade, vinculado ao neoliberalismo. 0 mesmo descaso pela transformação do sujeito observado no modelo tradicional de formação também ocorre quando a formação continuada é invadida pela lógica neoliberal, em que a verdade consumida prevê apenas a formação de habilidades e competências necessárias para o mercado, desfavorecendo, novamente, a formação ética do si mesmo. Esse é, predominantemente, o modelo contemporâneo de formação continuada.

No último momento, apresentamos a noção foucaultiana de cuidado de si lepiméleia heautoû), que, em contraposição às duas precedentes, nos permite pensar os processos de subjetivação do si mesmo pela perspectiva ética da verdade, que não só responsabiliza o sujeito pela sua própria formação como também promove os processos de formação a partir e em proveito do sujeito, o que permite transcender a força radical e autoritária da teoria, assim como aparece na metafísica, e a instrumentalização técnica da teoria, como é evidente na lógica neoliberal. Esse, portanto, é o modelo ético de formação continuada.

\section{MODELO TRADICIONAL DE FORMAÇÃO CONTINUADA: PENSAMENTO METAFÍSICO}

Há, nas mais diversas instituições de ensino, um cenário facilmente observável, que diz respeito ao modo como a formação continuada é planejada. Esse cenário reconhece uma posição privilegiada da teoria (educacional) em detrimento da realidade pedagógica e do próprio educador que nela atua. Para a grande maioria dos gestores educacionais, projetar os momentos de formação continuada, durante o ano letivo, é um desafio constante. "Como fazer?", "Quem convidar?" e "Qual a temática a ser abordada?" são questões que, comumente, se reservam às equipes diretivas, desconsiderando, muitas vezes, aquele a quem se destina a formação, ou seja, o próprio educador, que passa a assumir apenas o posto de objeto da formação, isso é, aquele a quem será oferecido determinado momento formativo. Com raras exceções, esse é o cenário predominante da formação continuada em nossas instituições educacionais.

Nesse contexto, as propostas formativas trazem verdades que estão, via de regra, desvinculadas do fazer pedagógico daquele cuja formação se quer promover e, por consequência, não atingem o campo do cotidiano formativo. São verdades de um conhecimento teórico que possui valor intrínseco, independente da condição do sujeito que a recebe e do contexto específico em que está inserido. Nossa hipótese, então, é de que essa proposta estaria refletindo uma concepção metafísica de formação humana. Pois, um 
lugar imperial, forte e preponderante sempre foi reservado à teoria (e às suas verdades) no decorrer da história do conhecimento. E, apesar de as críticas ao pensamento metafísico terem ganhado espaço no decorrer dos últimos dois séculos, atualmente, ainda encontramos posicionamentos metafísicos travestidos de posturas, supostamente, não metafísicas. ${ }^{8}$ Habermas (2002), ao colocar em pauta a legitimidade do rompimento da Modernidade com o pensamento metafísico, sugere, entre outras coisas, que a cisão com o logocentrismo que ampara uma dependência absoluta da prática em relação à teoria - foi decisiva para o nascimento do pensamento pós-metafísico.

Esse lugar privilegiado do conhecimento teórico, e do tipo de verdade que the corresponde, tem seus primeiros sinais na metafísica clássica grega (séc. IV a.C.) e se desdobra, de maneira preponderante, até Hegel, durante as primeiras décadas do século XIX (DALBOSCO, 2007). É um longo período, do qual ainda preservamos resquícios que se mostram no modo como nos comportamos em relação à teoria. A teoria, de modo geral, sempre exerceu certa autoridade sobre os individuos, sobretudo por lhes apresentar algo distinto do que costumeiramente é vivido, pois, em sua dimensão metafísica, a teoria pressupõe um distanciamento em relação à realidade humana. Assim, a teoria causa um estranhamento ao ser humano, pois, diferentemente da realidade concreta, pretende transmitir maior grau de coerência, de lógica, de certeza ou de verdade e, por consequência, tudo parece mais facilmente solucionável, pois ela anuncia uma compreensão diferente de mundo. Isso, por um lado, seduz, já que bastaria contemplá-la ou acessá-la de algum modo para que pudéssemos bem orientar nossos modos de vida. Porém, por outro, causa repulsa, à medida que apresenta, em geral, alto grau de complexidade e exige grande esforço para sua apreensão.

Apesar da fluidez do mundo contemporâneo (BAUMAN, 2001), que demonstra o rompimento com saberes fundantes e deterministas, supostos pela posição metafísica, as práticas cotidianas revelam, paradoxalmente, a aspiração dos indivíduos por um conjunto de verdades que possa abonar suas ações, sejam elas de ordem moral, técnica, cognitiva ou existencial. Esses posicionamentos que, ainda hoje, caminham ilusoriamente em direção a verdades essenciais, limitam a atuação do sujeito sobre os problemas reais do cotidiano, pois tais verdades têm origem em si mesmas e não na realidade singular dos indivíduos. De acordo com Habermas (2002, p. 22), nessa perspectiva, "o verdadeiro conhecimento tem a ver com aquilo que é pura e simplesmente geral, imutável e necessário." E é justamente nisso que consiste o modelo metafísico, pois pretende um conhecimento suprassensível em forma de sistemas com intenção de explicar o todo e tornar inteligivel o mundo humano, os modos de vida e a natureza. Por isso mesmo, seria o conhecimento metafísico um saber

8 Como teremos ocasião desenvolver mais bem na sequência do texto, entendemos por "metafisica" a postura fundamental que assume como possível um conhecimento objetivo da realidade tal qual ela se apresenta em si mesma em sua essência, esteja essa no mundo imanente ou transcendente. Com o adjetivo "metafísico/a" qualificamos o tipo de conhecimento e de verdade vinculado a essa posição. 
que fundamenta todos os outros saberes, enquanto um princípio racional no modo de uma primeira ciência, ou seja, um saber que vem antes de qualquer outro e que, por sua vez, seria também o fundamento comum e a condição de validade de qualquer possibilidade de verdade.

A preponderância da teoria é vista desde a educação antiga na Grécia Clássica, e, especialmente por inspiração platônica e aristotélica, sempre desejou alcançar a verdade, ou a verdadeira ciência (MARROU, 2017). A natureza da realidade, enquanto preocupação por excelência da metafísica, é elucidada via uma argumentação lógica, cujo rigor antecede e se sobrepõe à historicidade dos fenômenos empiricamente constatáveis. A garantia do conhecimento metafísico, então, assenta-se no exercício do raciocínio puro, desvinculado da história e da singularidade dos indivíduos, e, portanto, os modos de vida desses indivíduos são apenas "lugares" que devem ser adequados e legitimados em conformidade com aquela base conceitual atemporal. Sendo assim, os modos reais de vida dos indivíduos perdem seu potencial impulsionador da elaboração de um saber capaz de atuar e transformar, efetivamente, o sujeito.

A dinâmica da relação entre a teoria e a prática, quando prescrita pela metafísica, estabelece, assim, a verticalidade e a supremacia da primeira em relação à segunda, inibindo o diálogo entre os domínios. 0 enfraquecimento ou até mesmo o aniquilamento desse diálogo impossibilita o deslocamento da teoria para um campo mais simétrico, no qual a relação com a prática se dê de forma horizontal, permitindo ao sujeito, para além da pura contemplação de uma verdade teórica, confrontar a partir dela, também, a problemática que sempre caracteriza o seu cotidiano.

Mas isso não é o que preconiza de imediato a posição metafísica. Ao contrário, quando promovida pela perspectiva metafísica, a relação com a teoria libera o sujeito do confronto com o contexto imediato de sua prática; ao assumir a existência de conhecimentos cuja verdade tem uma garantia supratemporal, o sujeito, além de não se responsabilizar pela elaboração de tais conhecimentos, por vezes, também se esquiva de buscá-los por considera-los demasiadamente complexos. 0 conhecimento teórico representa, nessa perspectiva, uma verdade para poucos e, como resultado, quem a acessa possui algo que os outros carecem. Tal situação incita, na relação entre os sujeitos, o mesmo verticalismo visto na relação direta do sujeito com a teoria. 0 sujeito que está de posse dos conhecimentos metafisicamente garantidos detém em relação aos outros, despossuídos desse conhecimento, uma autoridade (supostamente) tão legítima quanto a verdade do conhecimento que possuem; uma autoridade que exige absoluta subordinação.

Em sua relação com a dimensão metafísica da verdade, a formação continuada conduz, assim, a uma primazia da teoria sobre o educador e sua prática docente. Essa concepção forte de teoria desprestigia o campo das experiências cotidianas como propulsor da própria formação do sujeito e, desse modo, a própria teoria, como fonte primária e 
autoritária de todo o processo formativo, tende, paradoxalmente, a tornar-se obsoleta. Dito de outro modo, quanto mais a formação se distancia das experiências cotidianas do sujeito para caracterizar-se pela relação como um conhecimento geral e atemporal, mais infértil ela se torna, pois não contribui, de fato, para a transformação do sujeito e de sua realidade.

No que diz respeito às instituições, a predominância da perspectiva teórica, sempre ligada ao universal, metafisicamente fundado, desprestigia a singularidade do sujeito (educador e educando) e dos fenômenos educacionais próprios de cada instituição. Em termos mais específicos, o que ocorre é que a contingência do educador e dos problemas formativos perdem valor diante de uma concepção universal de "educador" e de "educação". 0 mesmo se observa em relação aos sujeitos, que diante da pretensão metafísica de enunciar teorias confiáveis e seguras sobre os indivíduos e seus modos de vida, submete as individualidades a um saber geral e (enquanto tal) autoritário, que, ao mesmo tempo em que é capaz de promover a tranquilidade e a direção desejadas pelos indivíduos, reforça um êthos único que condiciona todo e qualquer indivíduo a padrões universais e dogmáticos que definem um mundo necessário em detrimento de um mundo possível.

A tendência do mundo contemporâneo é, grosso modo, rejeitar esse êthos único que permite apenas um mundo possível. ${ }^{9}$ De todo modo, apesar disso, ainda parece conveniente nos questionarmos se, no contexto contemporâneo, de fato, repudiamos toda e qualquer postura metafísica. Será que o mundo e o indivíduo contemporâneo de fato já se libertaram do pensamento metafísico? Abandonamos, realmente, o desejo por princípios universais, seguros e confiáveis? Já estamos plenamente preparados para vivermos em sociedades pluralistas, pós-metafísicas, que não apresentam um, ou pelo menos não apenas um, êthos definido? Estamos mesmo preparados para viver na ausência de verdades universais e deterministas?

Se, por um lado, o pensamento metafisico, atualmente, não se sustenta mais em seu modo conceitual, é notório que existem ainda espaços sociais em que se resguardam intensamente resquícios desse modo restritivo de compreender as práticas da relação sujeitoverdade. Supomos que um desses espaços é ocupado pelas instituições educacionais. 0 modelo de formação continuada que predomina nessas instituições dá testemunho disso. Ali, como já assinalamos, os processos formativos têm como ponto de partida, na maior parte das vezes, um conteúdo pedagógico determinado pelo formador como representante absoluto dos saberes seguros e confiáveis universalmente. 0 formador ocupa, portanto, um lugar privilegiado e, hierarquicamente, superior em relação ao formando e à realidade vivida no espaço pedagógico. Tal perspectiva parte dos seguintes pressupostos: todo formador domina absolutamente 0 conhecimento a ser transmitido; todos os sujeitos em formação são iguais entre si e têm as mesmas condições de aprendizagem; e, por consequência, toda a realidade pedagógica oferece

Conforme Beck (2011) e Elias (1994). 
os mesmos problemas formativos, os quais são solucionados por meio do mesmo conhecimento; ou seja, pressupõe-se que o conhecimento repassado pelo formador se encaixa perfeitamente a qualquer contexto educacional. Isso implica dizer que a verdade do formador, o sujeito em formação e a realidade pedagógica são consideradas concepções fixas e universais. Com base nesse pressuposto, são desconsideradas, entre outros aspectos, as reais dificuldades que o educador encontra, os limites e as fragilidades dos educandos e, sobretudo, as situações que a sociedade atual impõe quanto à formação humana.

A formação continuada é pensada pela perspectiva de um tema universal. Por consequência, o educador, alvo desse momento, não é protagonista de sua formação. Primeiro, porque o tema a ser tratado não surge de sua realidade pedagógica; segundo, porque ele abre mão dessa responsabilidade e a relega para a coordenação pedagógica ou para a equipe diretiva; e, terceiro, porque não tem, em si mesmo, a preocupação ou a consciência de transformar suas experiências pedagógicas em problemas formativos.

Esse contexto reduz o sujeito educador, em momentos de formação, a um espectador que aguarda o espetáculo a ser apresentado pelo protagonista da hora, o "formador", aquele que concentra em si a responsabilidade de promover a formação. Essa atitude passiva, que resume-se a contemplar o conhecimento verdadeiro trazido por outro, é resultado do modelo tradicional metafísico de formação em que o indivíduo se mantém fascinado com a promessa metafísica de que "[...] o abandono do enfoque natural mundano [...]" the permitiria "[...] o contato com o extraordinário." (HABERMAS, 2002, p. 42). Embora isso não signifique desconsiderar a possibilidade de um formador intervir no processo formativo do educador, o que devemos tensionar dessa situação é o lugar decisivo que o formador ocupa nesse modelo, em que está pressuposta uma concepção forte de teoria. Segundo Habermas (2002, p. 58), tal concepção, que prediz um caminho seguro de acesso à verdade e, ao mesmo tempo, fortalece uma "[...] significação salvífica da teoria", já devia, ainda no século XX, ter-se esvaecido. No entanto, entendemos que apenas se empalideceu, ressurgindo sempre em novos contextos, com outras vestimentas.

Essa configuração do conhecimento teórico, e a relação com a verdade a ele atinente, não pode, segundo Foucault, salvar o sujeito; apenas faz com que ele se distancie cada vez mais da teoria, pois dela guarda uma percepção vazia, já que the cabe apenas contemplar um conhecimento de difícil acesso e que, ao mesmo tempo, não the salva, ou melhor, não the prepara para atuar na realidade sobre a qual tal verdade pretende impactar e, especialmente, justificar-se enquanto verdade. Nesse universo, a concepção forte de teoria revela, paradoxalmente, seu lado fraco e vazio, pois, em razão de seu distanciamento da realidade vivida pelo educador, não contribui para a sua transformação ética enquanto sujeito da prática. Ao contrário, ela estabelece com o educador uma relação "salvífica", pois este acredita que estar de posse dos conceitos e manuseá-los, ainda que mecanicamente, 
seja suficiente para educar os outros, apenas em uma relação exterior, sem interferência formativa na subjetividade do próprio educando.

\section{O MODELO CONTEMPORÂNEO DE FORMAÇÃO CONTINUADA: A GESTÃO DE SI MESMO}

0 segundo cenário da formação continuada decorre da demanda neoliberal que impõe para a gestão de si mesmo a lógica da concorrência generalizada e a busca desenfreada pelo desempenho pessoal (DARDOT; LAVAL, 2017). Sob esse prisma, a formação continuada é entendida como aperfeiçoamento técnico do educador, que, por sua vez, deve educar os estudantes em vista de demandas sociais, quer dizer, deve também ele promover o sujeito ao sucesso, movido por interesses econômicos. Assim, se, no cenário anterior, tínhamos a descrição da formação continuada tradicional, fundada ainda na lógica metafísica, seletiva e autoritária, neste, temos a descrição da formação continuada contemporânea, fundada na lógica capitalista neoliberal, altamente excludente e não menos arbitrária.

0 neoliberalismo "é um sistema normativo que ampliou sua influência ao mundo inteiro, estendendo a lógica do capital a todas as relações sociais e a todas as esferas da vida." (DARDOT; LAVAL, 2016, p. 7). Nesse diagnóstico, em que é denunciado o lugar imperativo que o neoliberalismo ocupa frente à vida humana, que demarca o estado de condicionamento dos indivíduos a esse sistema normativo, podemos situar a pergunta pelos impactos desse sistema no modelo educacional, de modo geral, e, especificamente, no modelo de formação continuada do educador.

No arquétipo neoliberal de vida social, aprender ao longo da vida (life long learning) é condição imperativa do ser sujeito. Sem essa competência, não lhe será possível encontrar "seu" lugar no mundo. Produzir esse "capital humano" torna-se, então, função impreterível e imposta à escola. A educação é entendida, desse modo, como um bem privado e esse é o caminho vital para a manutenção do capitalismo neoliberal empresarial contemporâneo. Nesse contexto, as teorias (verdades) ou os conhecimentos tornam-se mercantilizados, pois passam a ter sentido e presença nas instituições educacionais somente à medida que visam fins econômicos. Cabe-nos, então, adiante, desenvolver essa pressuposição e, para tanto, mostrar a relação intrínseca entre o sistema neoliberal vigente e a constituição subjetiva do sujeito, bem como as implicações desse modelo relacional para os processos de formação continuada do educador.

A liberdade individual é o grande pilar do liberalismo clássico surgido ainda no século $\mathrm{XVII}$ e que, em sua versão atual, é reconfigurada segundo o contexto político e econômico de 
nossa época. Nesse cenário, os contornos contemporâneos da relação dicotômica e dependente entre sujeito e sistema ganham peculiaridades próprias e demarcam a subordinação do sujeito ao sistema, paradoxal e ilusoriamente, como um mecanismo de "liberdade".

Vivemos, hoje, o auge do neoliberalismo, cuja proposição fundamental é a intervenção mínima do Estado na vida privada do indivíduo e no mercado. As ideias estão interligadas, pois se supõe que ao minimizar, política e economicamente, o Estado, seguirse-á a consequente ampliação da liberdade individual. Entretanto, o risco eminente dessa configuração é o avanço do domínio do mercado, em função de seu perfil capitalista, sobre o modo de vida dos cidadãos. Esse movimento é legitimado pelo Estado, que se vê invadido pela lógica mercantil de pensar e administrar.

A liberdade individual, como núcleo do projeto neoliberal, se volta para interesses externos ao sujeito, com finalidade explícita de garantir a sustentabilidade do sistema econômico. A liberdade, assim, em nada vincula-se com a autoconstituição ética e autônoma da subjetividade humana, pelo contrário, apesar de ser compreendida enquanto processo de autogestão, esse "empresariamento" de si mesmo seria, apenas, condição impreterível do homo economicus, que passa a administrar a si mesmo com fins predominantemente financeiros. Sem essa dimensão teleológica da "liberdade" humana, o indivíduo, em sua singularidade, não é reconhecido socialmente. A aparente liberdade individual, então, pressupõe a adequação do indivíduo a um conjunto de princípios previamente determinados. Apesar disso, vale lembrar que a gestão de si mesmo não é, necessariamente, um mecanismo nocivo à vida humana, ela somente passa a assumir esse caráter à medida que adota fins capitalistas e neoliberais, em razão dos quais o sujeito esquece-se de si mesmo para apegar-se àquilo que the é externo.

Se o indivíduo não tem valor em si mesmo e para si mesmo, mas relativamente à sua pertinência ao sistema produtivo mercantilista, então sua formação não terá de se justificar com base em projetos e escolhas subjetivas. E, de fato, nesse contexto, a formação passa a responder, quase exclusivamente, pela busca desenfreada por um lugar economicamente privilegiado, reservado apenas a alguns, uma vez que o sistema não contempla a todos de igual modo, fomentando, dessa forma, uma competitividade selvagem e excludente. Pode mais aquele que está adequadamente qualificado e ajustado às regras do jogo do sistema econômico. Na relação com o sistema, o sujeito não tem primazia sobre si mesmo, ele é apenas um recurso necessário para o sucesso daquele, que, concomitantemente, retribui a esse sujeito preparado e qualificado com vantagens que o próprio sistema o faz desejar ao longo de sua vida. A satisfação desses desejos vem travestida de liberdade individual.

Assim como faz com a liberdade, a racionalidade econômica neoliberal subverte outros conceitos caros à formação humana e às formas éticas de vida, alicerçadas na cooperação solidária e no respeito recíproco. A subversão desses princípios é facilmente observada no tipo de valorização que recebem do mercado, que os enaltece na medida 
em que e porque promovem acréscimos na rentabilidade das empresas. Ou seja, de modo cooperativo e empreendedor, os sujeitos não somente produzem mais como também se sentem parte do processo. Há, nisso, um mecanismo conveniente de convencimento, aceitação e envolvimento massivo e alienado em prol da maquinaria das empresas.

Assim, o cuidado de si no interior do sistema neoliberal vem idealizado de sucesso financeiro, que assume o lugar mais pretendido da realização humana. 0 não alcance desse escopo é mostrado como resultado da fraqueza e da incompetência do próprio sujeito que falha ao gerenciar a si mesmo, segundo as regras do jogo. Não cabe ao sistema assumir qualquer culpa ou responsabilidade pelo fracasso ou pelo sucesso individual. Por isso, o máximo desempenho, que se traduz em resultados econômicos satisfatórios ao sujeito, exala a satisfação pretendida por ele e fortalece as regras do jogo que, concomitantemente, regulam sua subordinação ao sistema. Os que não alcançam esse lugar consolam-se ao aceitar a ideia de que eles mesmos não foram capazes, apesar da "liberdade" e das oportunidades dadas pelo sistema.

Há, como vemos, forte invasão dos ditames neoliberais na vida humana e isso também refletirá, de modo mais específico, nas instituições escolares. Imersa na lógica neoliberal, a escola "[...] considera a educação como um bem, essencialmente, privado e cujo valor é, antes de tudo, econômico." (DARDOT; LAVAL, 2016, p. XI). Com fins reduzidos à perspectiva individual, esse modelo de escola promove a capitalização de recursos privados por parte do educando, o que contribui para "formar" o indivíduo vorazmente competitivo para o mercado de trabalho. A escola é, nessa configuração, como nos diz Laval (2004), um indicador de competitividade individual. Tal perspectiva difere da escola republicana, que se ocupava em formar o cidadão, e que

\footnotetext{
[...] encontrava seu centro de gravidade não somente no valor profissional mas também no valor social, cultural e politico do saber, valor que era interpretado, de resto, de maneira muito diferente segundo as correntes políticas e ideológicas, está orientada, pelas reformas em curso, para objetivos de competitividade que prevalecem na economia globalizada. (LAVAL, 2004, p. XIII).
}

A partir do avanço da lógica neoliberal, notamos uma inversão de posicionamentos entre a escola e o mercado, pois "em educação [...], não se trata mais de corrigir as imperfeições do mercado pela intervenção do Estado [...]”, mas - e isso é absolutamente degradante para a noção de Estado - "[...] de suprir as fraquezas do Estado pela promoção do mercado [...]" (VINOKUR, 1999 apud LAVAL, 2004, p. 13-14). Dito de outro modo, cabe aos métodos de gestão do mercado ajustar as fragilidades da gestão estatal, subordinando sobremodo qualquer projeto de nação no que diz respeito à formação do povo. Na medida em que esse projeto ganha 
força, a economia passa a ser colocada "L... mais do que nunca, no centro da vida individual e coletiva, sendo os únicos valores sociais legítimos os da eficácia produtiva, da mobilidade individual, mental e afetiva e do sucesso pessoal." (LAVAL, 2004, p. 15).

Nos processos de gerenciamento de si mesmo, a educação, na lógica neoliberal, apresenta-se como uma referência por excelência da possibilidade de sucesso na dinâmica de inserção social, pois a noção de sujeito de sucesso nesse cenário exige rentabilidade individual que fortalece a relação entre $o$ consumismo e a empregabilidade. 0 sucesso do individuo neoliberal implica a garantia do emprego mais rentável possivel, o que não somente assegura a rápida, massiva e eficaz produtividade das empresas por meio do desempenho técnico desse indivíduo, como, também, afiança o retorno dessa economia para a própria empresa por meio do consumismo desse mesmo sujeito de sucesso. A acumulação de capital torna-se, assim, o fim único e definitivo do sujeito contemporâneo e, por isso, esse individuo entende-se plenamente à medida que "L...] o livre uso da mercadoria se torna a forma social dominante do prazer dos sentidos e do espirito." (LAVAL, 2004, p. XVI).

Ainda de acordo com Laval (2004), o neoliberalismo se apresenta como modo de resolução de disfunções presentes nas sociedades, a exemplo dos anseios de igualdade em detrimento da divisão social de classes. Entretanto, a igualdade pretendida nas sociedades neoliberais se reduz, por parte do individuo, à sua liberdade em tentar alcançar rentabilidade econômica cada vez maior, conforme sua condição. Entendida dessa forma, a igualdade entre os indivíduos se enfraquece e, por consequência, também mingua o empenho por acesso à cultura e à formação integral. Ao se enraizar na sociedade como um todo, a lógica mercantil domina os ideais de constituição do sujeito e, por consequência, faz da escola um mecanismo para atingir esse ideal. E, de forma ainda mais nefasta, relega a responsabilidade do alcance desse ideal ao próprio indivíduo, isentando-se de propor um projeto coletivo e igualitário de formação e de recepção das novas gerações na sociedade. Uma inserção social que, alás, é reduzida apenas a uma inserção profissional e, para isso, a formação de habilidades para atender ao mercado de trabalho é absolutamente suficiente para descrever o papel da educação. Por conta disso, a escola tem valor no seio social apenas enquanto, em função de sua presteza profissionalizante, preparar o individuo para a competitividade econômica.

Como sintoma imediato desse quadro, vemos a escola e o educador tomar emprestado da racionalidade empresarial aparatos que assumirão papel pedagógico. Nas palavras de Laval (2004, p. 261), "[...] a administração escolar, em sua preocupação de racionalização mais potente do ensino, empresta remédios e retóricas do gerenciamento privado pretendendo, assim, melhor adaptar a escola à 'demanda social." Nesse sentido, e sempre em vista da mais alta performance de si mesmo, percebe-se inúmeros momentos de "reciclagem" ou de treinamento vividos pelos individuos na busca de atualização dos conhecimentos e adaptação às novas tecnologias, ambas exigências da empregabilidade. 
0 sentido e a promoção da educação sempre pressupuseram um ideal de ser humano a ser alcançado. ${ }^{10} 0$ neoliberalismo, por sua vez, também traz consigo um ideal humano, e os "novos homens" a serem formados, diz Laval (2004), são os trabalhadores e os consumidores do futuro: "depois do crente, depois do cidadão do Estado, depois do homem cultivado do ideal humanista, a industrialização e a mercantilização da existência redefinem o homem, como um ser essencialmente econômico e como um indivíduo essencialmente privado." (LAVAL, 2004, p. 43). Nessa perspectiva, o ser humano resume-se a um "recurso", sendo que a linguagem empresarial entende o "recurso humano" como uma ferramenta necessária para se atingir uma meta. 0 ser humano, desse modo, desocupa o lugar central e privilegiado que deveria ter na sociedade, na política e no ideário educativo, para apresentar-se como meio para atingirem-se as metas do sistema.

Esses novos referenciais normativos provocam a reforma liberal da escola desde suas práticas pedagógicas até seu modelo administrativo. 0 conteúdo programático, por exemplo, passa a ser diretamente presumido, sendo que até mesmo "a 'formação inicial', devendo servir à aquisição de uma 'cultura' de base orientada em função de motivos profissionais amplamente compreendidos, reclama uma pedagogia governada pelos imperativos da inserção profissional [...]" (LAVAL, 2004, p. 46). A bagagem cultural repassada pela escola deve atender apenas ao básico para as atividades profissionais futuras, deixando espaço suficiente para a atuação formativa futura desse profissional pela empresa, que buscará associá-la decisivamente à produção.

Nesse sentido, "o essencial repousa na capacidade do trabalhador de, durante toda a sua existência, aprender o que lhe será útil profissionalmente." (LAVAL, 2004, p. 49). 0 núcleo dessa educação reside na capacidade de adaptação às exigências do mercado, que são, cada vez mais, transitórias. As competências básicas promovidas pela educação inicial tornam-se comercializáveis na medida em que permitem a devida adequação do empregador ao que esperam o mercado e a empresa. É isso que faz do indivíduo um recurso humano que acumula um capital cultural competitivo, porque contempla o mais alto e mais desejável desempenho pessoal. Se sobressai nessa incessante competição aquele que melhor gerenciar a si mesmo. A educação, portanto, ignora o bem comum, a vida coletiva, os princípios de solidariedade e generosidade, transformando-se por essa via em um bem privado.

A formação continuada, nos parâmetros do neoliberalismo, instrumentaliza o conhecimento (a teoria) ao passo em que indica que cuidar de si mesmo é constituir um perfil profissional competitivo, que esteja hábil a aprender a aprender ao longo da vida. Isso permite aos sujeitos gerenciar as inseguranças vindouras e garantir a empregabilidade. Por outro viés, remete a um tipo de saber que subverte o cuidado de si mesmo ao abandonar

10 Salvo as teorias anarquistas da educação, como esclarece Gallo (1996). 
o interesse pela formação ética do sujeito. 0 educador, de todo modo, quando inserido nessa lógica social e, também, educacional, vê-se compelido a compreender o diálogo com a tradição pedagógica e filosófica como uma inutilidade, já que não serve imediatamente para a resolução dos problemas pedagógicos e nem para a ampliação de seu desempenho específico, conforme exigido pelo mercado.

\section{O MODELO ÉTICO DA FORMAÇÃO CONTINUADA: A PERSPECTIUA DO CUIDADO DE SI}

A aproximação da filosofia de Michel Foucault (1926-1984) com a questão da formação humana ganha sensível estreitamento na última fase de seu pensamento," especialmente em razão de seus estudos relacionados à noção de epiméleia heautoû "cuidado de si". Tal noção, de maneira geral, radicaliza a responsabilidade de cada um consigo mesmo e, portanto, postula que o si mesmo é, ou poderia ser, de fato, uma criação própria conduzida por meio de "[...] práticas subjetivantes pelas quais o sujeito pode pensarse enquanto sujeito." (ARAÚJ0, 2008, p. 93, grifo do autor). De todo modo, refletir a respeito da relação entre cuidado de si e formação humana, na perspectiva de que "criamos a nós mesmos", não é nada trivial ou inequívoca. De fato, a noção de "cuidado de si" está adentrando, cada vez mais, no campo formativo, pois se apresenta como um aspecto reflexivo capaz de ancorar o sentido crítico-constitutivo à formação do sujeito, para que ele possa se posicionar frente aos desafios existenciais, éticos e políticos com os quais se depara.

0 cuidado de si é uma noção milenar, que data, aproximadamente, dos séculos IV e V a.C., e demarca as origens da filosofia na Grécia Antiga. Coube a Foucault o resgate dessa noção e a devida reinserção dela na vida da filosofia. Cabe a nós, entretanto, avaliar a efetividade de sua presença nos mais diversos campos de atuação da vida humana. $\mathrm{Na}$ filosofia, o cuidado de si nasce com a figura de Sócrates, diante de sua posição (taxe) de incitar os outros a ocuparem-se consigo mesmo. No diálogo platônico Apologia de Sócrates (36c), em seu juízo final, Sócrates proclama: “senhores atenienses, não há que atender a

\footnotetext{
" Frequentemente, o pensamento de Michel Foucault é dividido em três fases. [a] a primeira refere-se à chamada Arqueologia, predominantemente nos anos 1960, em que a base investigativa se assenta nas pesquisas sobre as práticas discursivas da ciência e nas regularidades que thes era imanentes; [b] a segunda trata-se da Genealogia, que vigorou nos anos 1970, concentrando-se nas práticas de poder e nas formas de conhecimento que as sustentavam e; [cl a terceira e última fase aborda a questão Ética e abarca seus últimos estudos, também habitualmente denominada de "o último Foucault", cuja proposta investigativa centrou-se na constituição subjetiva do sujeito por meio de práticas éticas e exercícios de si. Marcam esse momento tanto suas obras acerca da História da Sexualidade quanto seus cinco últimos cursos dados no Collège de France, que foram publicados sob os títulos Do Governo dos Vivos (1979-1980), Subjetividade e Verdade (1980-1981), A Hermenêutica do Sujeito (1981-1982), O Governo de Si e dos Outros (1982-1983) e A Coragem da Verdade (1983-1984).
} 
nenhuma de vossas coisas antes que a vós mesmos." (PLATÃ0, 2015). Por isso, diz Foucault (2004, p. 7): "[...] Sócrates apresenta-se como aquele que, essencialmente, fundamental e originariamente, tem por função, ofício e encargo incitar os outros a se ocuparem consigo mesmo, a terem cuidados consigo e a não descurarem de si."

Sócrates torna-se o modelo paradigmático do cuidado de si no curso $A$ Hermenêutica do Sujeito proferido por Michel Foucault, em 1982, no Collège de France. 0 filósofo grego sempre teve, segundo Foucault, um olhar próprio, original e legítimo sobre si mesmo. Exemplo disso é registrado quando o Oráculo de Delfos the instituiu como o mais sábio entre os sábios e, apesar disso, ele não aceita, passivamente, esse título (titulação). Nessa ocasião, ele se pôs a investigar se, de fato, era merecedor dessa distinção e, todavia, se o título representava sua posição no mundo. Passou a vida toda, até o último instante antes de sua morte, colocando sua vida à prova ao investigar, incessantemente, a legitimidade de seu título de sábio.

Para tanto, Sócrates se propôs ir ao encontro dos supostos "sábios" da época (políticos, artífices, poetas...) e descobriu que possuía uma "pequena" diferença em relação a eles: enquanto aqueles "sábios" acreditavam conhecer, verdadeiramente, alguma coisa, Sócrates sabia que não conhecia nada verdadeiramente. Sendo assim, ele diferenciava-se dos outros por um pequeno detalhe de sabedoria, isso é, pela ínfima descoberta de que tem consciência de sua ignorância. Porém, essa quase insignificante diferença resulta de um supremo exercício de si sobre si. Uma pequena diferença no quesito sabedoria, mas uma imensa diferença no que diz respeito à prática de si mesmo.

0 cuidado de si é, então, um modo específico de se posicionar perante a si mesmo. Essa direção de toda sua atenção a si mesmo, durante sua existência, não resulta meramente do autoconhecimento. 0 conhecimento de si mesmo, ainda que entendido como um movimento introspectivo, é apenas uma instância do cuidado de si, pois precisa retornar sobre o sujeito que se conhece, numa espécie de conversão a si (epistrophé) capaz de influenciar o modo de ser do sujeito. E esse conhecimento, ao se tornar logos de ação, transfigura o si mesmo. A aquisição de um conhecimento não tem, nesse sentido, qualquer valor de verdade. Somente quando ele é colocado à prova, ou seja, somente ao passo em que é vivido pode adquirir, portanto, valor de verdade, pois doravante modifica o modo de ser do sujeito. Essa dinâmica da verdade é chamada por Foucault de saber de espiritualidade.

A formação continuada, do modo como a entendemos, é, por excelência, esse olhar atento sobre si mesmo, sobre o que se passa no pensamento e sobre os modos de agir. Uma vez perdida essa dimensão, amplia-se a distância entre os problemas reais que assolam a vida humana, impedindo, desse modo, que o saber adquirido retorne sobre o sujeito, transfigurando-o. Diz Foucault (2004, p. 116) que o principal objetivo do cuidado de si é "tornarmo-nos o que nunca fomos [...]" 
Continuar sendo o que somos é o que a formação continuada pretende combater. A transformação de si mesmo por si mesmo em algo que nunca havia sido é o que propõe o cuidado de si. 0 estado de manter-se como se é, ou tornar-se qualquer coisa que foge daquilo que o próprio sujeito direciona é o que Foucault denomina de stultitia. Ao apoiar-se na carta 52 de Sêneca a Lucílio, Foucault (2004, p. 161) define o stultus como aquele que não assume a responsabilidade sobre si mesmo, aquele a "[...] que nada se fixa e que em nada se apraz." Stultus é quem ainda não iniciou o cuidado de si mesmo, quem ainda não se apercebeu como alguém que precisa sair de um determinado estado.

Em outras palavras, o stultus é "[...] aquele que está a mercê de todos os ventos, aberto ao mundo exterior, ou seja, aquele que deixa entrar em seu espírito todas as representações que o mundo exterior the oferece." (FOUCAULT, 2004, p. 162). Por tais características, a stultitia se caracteriza como um dos maiores riscos para a introdução do descompromisso ético do educador consigo mesmo e com o outro. 0 stulto deixa simplesmente as estruturas, os modelos, as representações externas e próprias da cultura dominante entrar em seu espírito, sem fazer a discriminatio, isso é, sem proceder a separação, o exame ou a análise daquilo que constituirá sua própria subjetividade e, por consequência, seu modo de agir e se posicionar no mundo, como fez Sócrates frente ao oráculo.

0 posicionamento no mundo requer a elaboração vagarosa, consistente e refletida sobre a vida, resultado da discriminatio. Ao contrário, "[...] o stultus é aquele que está disperso no tempo" (FOUCAULT, 2004, p. 162), no sentido em que não está apto a identificar ou a entender o que o tempo em que se vive representa para si mesmo e, desse modo, não consegue se colocar em um lugar proveitoso, conveniente e ético. Há, no stultus, uma abertura irreprimível para a multiplicidade do mundo e, por conta disso, nada é elaborado, selecionado ou construído que tenha a sua assinatura, que seja resultado de sua autonomia intelectual. Está a mercê de todos os ventos, disponível a qualquer determinação exterior, entregue às mudanças incontroláveis de opinião. E "[...] a consequência [...] desta abertura às representações que vêm do mundo exterior e desta dispersão no tempo é que o indivíduo stultus não é capaz de querer como convém." (FOUCAULT, 2004, p. 163).

0 stultus confronta o conhecimento (e a verdade a ele atinente) como elementos externos, em relação aos quais ele ou se mantém alheio ou se subordina irrefletidamente. $A$ verdade que vem de fora e que subjuga o stultus não tem, contudo, força transformadora. Para que a transformação aconteça é preciso que o sujeito assuma posição em relação à verdade, que busque se apropriar dela mediante esforço e disciplina da vontade. Mas isso não tem lugar espontaneamente, pois a vontade do stultus o leva para outra direção. 0 esforço para a superação da stultitia é, por isso, antes de tudo, um trabalho do sujeito em relação às carências de seu querer. 
Foucault apresenta três características da vontade do stultus que o mantém em sua condição, afastando-o do querer autêntico. A primeira remete ao fato de a vontade do stultus não ser um querer livre, uma vez que é determinada pelas representações do exterior e pelo que vem de seu interior, seus desejos, paixões e vicissitudes. Isso se justifica em razão de que o stultus, além de não conseguir fazer a discriminatio do que vem do exterior, também não consegue dominar seus apetites e desejos. A segunda característica ressalta que o stultus não quer absolutamente, ou seja, quer várias e diferentes coisas ao mesmo tempo. Não consegue, então, determinar sua vontade, pois se interessa por todas as coisas que the parecem sugestivas, inclusive por aquelas inconciliáveis, por exemplo, "[...] quer a glória e, ao mesmo tempo, lastima por não levar uma vida tranquila [..." (FOUCAULT, 2004, p. 163). Por fim, a terceira característica da vontade do stultus mostra-se no fato de que, mesmo quando ele define um querer, trata-se de uma vontade que se quer com frouxidão, com indolência, que se interrompe facilmente.

A vontade do stultus, então, não é livre, nem absoluta e nem permanente. Tais carências comprometem a possibilidade do cuidado de si, do ocupar-se consigo mesmo, pois para tal seria preciso querer, livre, absoluta e permanentemente, o si mesmo. Ao querer todo o resto, que não o si mesmo, o educador stultus passa a desejar para a sua formação não a autoformação, a transformação de si mesmo, mas técnicas e alternativas para desenvolver em sala de aula; ele quer conhecimentos e verdades prontas que incrementem sua prática sem colocarem em jogo seu ser como educador. Nessa perspectiva, qualquer metodologia ou proposta inovadora proveniente de palestras e cursos torna-se conveniente aos sujeitos que a acompanham, pois, sem a preocupação e a atenção voltada para si mesmo, nada podem discriminar daquilo que lhes é apresentado.

Quando não se quer de forma livre, absoluta e permanente a si mesmo, não se torna possível cuidar de si, e, ao descuidar de si mesmo, o sujeito não posiciona-se firmemente no mundo de modo suficiente para intervir na sua própria constituição. Da mesma maneira, não se engaja eticamente em relação ao outro, pois não tem autonomia e autoridade para construir uma relação plena. Na ausência do cuidado de si, a posição frente ao outro tende a fundamentar-se no autoritarismo ditado por seus apetites, paixões, interesses ou qualquer outro aspecto que esteja misturado em sua subjetividade, sem discriminação, clareza e nitidez.

Assim, a formação continuada tende a desconsiderar o grupo, não consegue se envolver com o problema do outro como um problema coletivo. Para romper com a dimensão individualista, de querer resolver imediata e unicamente seus próprios problemas, é necessário cuidar de si, querer a si mesmo de forma livre, absoluta e permanentemente; pois, sem esse querer que se estabelece na relação consigo mesmo, reduz-se também a possibilidade de respeitar a mesma postura no outro. Não é somente uma questão de respeito, mas de 
incentivo e propagação. Sócrates, enquanto modelo exemplar do cuidado de si, passou a vida despertando e inquietando o outro a cuidar de si, postura oriunda no cuidado que ele próprio dedicava a si mesmo, pois sabia que "não se deve fazer passar o cuidado dos outros na frente do cuidado de si; o cuidado de si vem eticamente em primeiro lugar, na medida em que a relação consigo mesmo é ontologicamente primária." (FOUCAULT, 2014a, p. 265).

Entender a formação continuada como autoformação de si mesmo é opor-se energicamente a qualquer indiferença ou desconsideração do outro, do mundo, do coletivo. A questão, sob esse aspecto, está em entender que, sem o cuidado de si, o cuidado do outro se atenua e se reduz ao esquecimento. É nítida, portanto, a importância da formação continuada vista pela via do cuidado de si. 0 educador que não se ocupa consigo mesmo não consegue ocupar-se como convém do outro, pois o mestre, para contribuir com a saída do stultus de seu estado, precisa ser experimentado na arte do cuidado de si, ou seja, sem se entregar às vicissitudes, não saberá qual o objeto do cuidado de si, nem como transformá-lo.

\section{CONSIDERAÇÕES FINAIS}

Foucault (2017), ao tratar da pergunta "como governar a si mesmo?", propõe que tal questão deve ser precedida por outra: "como não ser governado?". Em outras palavras, reflete se "é possível formarmos a nós mesmos?", por meio da questão "como não ser formado?". Isso não significa "não querer ser formado", mas "não querer ser formado deste ou daquele modo", e tal procedimento tem origem no lugar e no papel que atribuímos ao conhecimento e à verdade, e, também, no modo com que nos relacionamos com ela.

Sendo assim, antes mesmo da instituição e da função dos gestores educacionais, a responsabilidade pela formação continuada é do próprio educador. Ele tem, previamente, um compromisso com o mundo que é inalienável e que the exige, como vimos, responsabilidade para consigo mesmo. Entretanto, o risco eminente que o sujeito corre ao romper com a tendência metafísica é de reduzir a formação continuada a um telos produtivista voltado a consentir as demandas do mercado capitalista, uma vez que a formação continuada é invadida pelo desejo de alta empregabilidade, gerado pelo esperado desempenho de si mesmo.

É notável, portanto, que em nenhum desses dois modelos de formação continuada - o metafísico e o neoliberal - o sujeito e seus problemas ético-existenciais são tomados como ponto de partida para orientação de seus estudos. Isso é, o próprio processo formativo do ser humano não o toma como origem e motivação, tampouco o tem como fim. Vista desse modo, a formação continuada nada tem a ver com um apelo à excelência pedagógica do 
educador em formar eticamente o educando para a vida, que nos parece imprescindivel. Salta aos olhos, assim, a importância e a prudência com que devemos voltar a esse tema.

A formação continuada enquanto ética do cuidado de si é, também, uma formação ao longo da vida. Porém, essa formação não implica uma adaptação do sujeito ao social, mas um fortalecimento dele perante as influências externas. 0 sujeito ético do cuidado de si ocupa-se consigo mesmo quando traz à sua reflexão e atuação seu próprio ser, seu próprio comportamento cotidiano e, em especial, tudo aquilo que se passa em seu pensar. Desse modo, o cuidado de si implica colocar o si mesmo sempre em evidência. É a verdade elaborada pelo sujeito, cotidianamente, ao colocar sua realidade em permanente diálogo consigo mesmo que é capaz de salvá-lo, primeiramente de si mesmo e, por consequência, do autoritarismo externo, provindo do sistema. Se entendida pelo cuidado de si, a formação continuada pode significar, portanto, um modo de transformação.

\section{REFERÊNCIAS}

ARAÚJO, I. L. Foucault e a Crítica do Sujeito. 2. ed. Curitiba: Ed. da UFPR, 2008.

BAUMAN, Z. Modernidade líquida. Rio de Janeiro: J. Zahar, 2001.

BECK, U. Sociedade de risco: rumo a uma outra modernidade. 2. ed. São Paulo: Editora 34, 2011.

BRASIL. Congresso Nacional. Câmara dos Deputados. Centro de Documentação e Informação. LB: Lei de Diretrizes e Bases da Educação Nacional: lei n 9.394, de 20 de dezembro de 1996, que estabelece as diretrizes e bases da educação nacional. 14. ed. Brasília, DF: Câmara dos Deputados, Centro de Documentação e Informação, 2017. Disponivel em: https://secure.upf.br/pdf/PDF de Livro/LDB14ed.pdf. Acesso em: 3 jul. 2018.

DALBOSCO, C. A. Pedagogia Filosófica: cercanias de um diálogo. São Paulo: Paulinas, 2007.

DARDOT, P.; LAVAL, C. A nova razão do mundo: ensaio sobre a sociedade neoliberal. São Paulo: Boitempo, 2016.

DARDOT, P.; LAVAL, C. Comum: ensaio sobre a revolução no século XXI. São Paulo: Boitempo, 2017.

ELIAS, N. A sociedade dos indivíduos. Rio de Janeiro: Jorge Zahar, 1994.

FOUCAULT, M. A hermenêutica do sujeito: curso dado no Collège de France (1981-1982). Edição estabelecida sob a direção de François Ewald e Alessandro Fontana, por Frédéric Gros. Tradução: Mário Alves da Fonseca e Salma Tannus Muchail. 3. ed. São Paulo: Editora WMF; Martins Fontes, 2004.

FOUCAULT, M. Ditos e escritos V. Ética, sexualidade, política. 3. ed. Rio de Janeiro: Forense Universitária, 2014a. 
FOUCAULT, M. Entrevista com Michel Foucault. In: FOUCAULT, M. Ditos e escritos IX: genealogia da ética, subjetividade e sexualidade. Rio de Janeiro: Forense Universitária, 2014b.

FOUCAULT, M. 0 que é a Crítica? Seguido de A Cultura de Si. Tradução: Pedro Elói Duarte. Lisboa: Edições Texto e Grafia, 2017.

GALLO, S. 0 paradigma anarquista em educação. Nuances, v. 2, set. 1996.

HABERMAS, J. Pensamento pós-metafisico: estudos filosóficos. Rio de Janeiro: Tempo Brasileiro, 2002.

LAVAL, C. A escola não é uma empresa: o neoliberalismo em ataque ao ensino público. Londrina: Editora Planta, 2004.

MARROU, H.-I. História da Educação na Antiguidade. Tradução: Mário Leônidas Casanova. Campinas, SP: Kirion, 2017.

MÜHL, E. H.; DALBOSCO, C. A.; CENCl, A. V. Questões atuais da educação: sociedades complexas, pensamento pós-metafisico, democracia e formação humana. ljuí: Ed. Unijuí, 2016.

PLATÃO. Apologia de Sócrates. Críton. Tradução: Carlos Alberto Nunes. Editor convidado: Plínio Martins Filho. Organização: Benedito Nunes e Vitor Sales Pinheiro. Texto grego: John Burnet. 3. ed. rev. e bilíngue. Belém: Ed. UFPA, 2015.

Endereço para correspondência: BR 285, Bairro São José, Passo Fundo, Rio Grande do Sul, Brasil; miguel.rossetto@upf.br

Roteiro, Joaçaba, U. 46, jan./dez. 2021 | e22401 |E-ISSN 2177-6059 
